\title{
Real-Time On-Board HMS/Inspection Capability For Propulsion and Power Systems
}

\author{
Sarkis Barkhoudarian \\ Rocketdyne Propulsion and Power Division, Canoga Park, California 91309
}

\begin{abstract}
Presently, the evaluation of the health of space propulsion systems includes obtaining and analyzing limited flight data and extensive post flight performance, operational and inspection data. This approach is not practical for deep-space missions due to longer operational times, lack of in-space inspection facility, absence of timely ground commands and very long repair intervals. This paper identifies the on-board healthmanagement/inspection needs of deep-space propulsion and thermodynamic powerconversion systems. It also describes technologies that could provide on-board inspection and more comprehensive health management for more successful missions.
\end{abstract}

\section{Introduction}

\section{A. Current Health Management Approach}

Current space-propulsion system on-board Health Management Systems (HMS) provides partial data about the health of liquid-propellant propulsion systems in real time. This data is telemetered to earth for real-time review and immediate shutdown commands during approximately 500 seconds of engine operation. Additional HMS data is obtained after the return to earth. In addition, extensive post-flight manual inspections are performed, requiring removal of engines from the vehicle and disassembly of the engines. These inspections require complex tools and elaborate disassembly and reassembly, followed by leak tests, binding-torque measurements, etc. They check the internal erosion, corrosion, chipping, rotary system rubbing and radial/axial plays, etc. Present space-propulsion engines need ground commands for safer operation during the launch. Current on-board controllers use two control variables in real time and shut the engine down when a predetermined parameter, e.g. temperature, pressure or RPM, exceeds its threshold level. They typically can not respond to multiple failures. As can be seen, current controller/HMS/inspection cannot meet the requirements of deep-space propulsion or thermodynamic powerconversion systems.

\section{B. Modern HMS/Inspection Needs}

The HMS for deep-space propulsion and power-conversion systems will require very intelligent and autonomous engine controllers that function for a much longer operational time, while performing real-time automated inspection and fault mitigation. They must provide early life assessment, and diagnostic and prognostic information, based upon the engine performance and hardware degradation in real time. They will need adaptive control capability to optimize performance and mitigate operational anomalies and hardware degradation. The failure symptoms must be detected when the failure is in very early stages of development. This will require novel sensor technologies capable of rapidly providing increased awareness of the entire propulsion and power-conversion system health. It will also require advanced algorithms that can be used to detect the symptoms, predict consequence of the failure, and mitigate faults in real time. Ideally, modern HMS will require an active healthcontrol manager that can in real time provide automated diagnostics, prognostics, optimiziation, and repair. Furthermore, it will require collection of real-time data that should be processed dynamically, resulting in more rapid identification of off-normal conditions and enabling reliable corrective actions to ensure mission success and safety. It will also require on-board plant archived data to better diagnose problems before they become critical. 


\section{Solution}

Comprehensive fault-detecting and fault-mitigating propulsion and power-conversion systems are needed. Ideally, all hardware degradation types must be identified, monitored and mitigated. They include fatigue, wear, erosion, corrosion, leakage, rotary component run-outs, rubbing, fluid and dynamic instabilities, etc. In addition, multidimensional mapping of exterior surface anomalies such as strain, vibration, and temperature are needed to provide comprehensive knowledge of the health of the hardware, rather than just single-point information. Advanced sensors are needed capable of monitoring these degradations and provide multidimensional measurements. Advanced algorithms are needed to process and fuse the data; diagnose, prognose and mitigate the failures; and prevent catastrophes. Such advanced integrated HMS/control systems provide additional tiers of health assessment far beyond the present shut-down or throttle-down systems.

\section{Approach}

New sensors are being developed for rocket engines to enable automated health assessment and management instead of traditional manual inspections. In addition, intelligent engine algorithms are being developed. These technologies must be developed to an acceptable level of readiness. Through the use of advanced sensors and algorithms, the life of critical hardware could be measured and significantly prolonged and mission success improved, while reducing the maintenance/inspection cost. Examples of these advanced technologies are described below.

\section{Advanced Technology Description}

\section{A. Measurement Technologies}

Advanced measurement technologies must be, as much as possible, nonintrusive, remote, multifunctional and multidimensional to minimize interference with the operation of the propulsion and power-conversion systems. These features will increase the reliability of sensors and allow comprehensive assessment of the health of the entire system. Furthermore, direct-monitoring, rather than inferred, must be used as much as possible. They monitor the phenomenon directly and reduce false alarms due to inaccurate inference. They will provide more robust HMS/inspection systems, capable of handling even multiple-failure anomalies.

Multiparametric sensors provide information of more than one parameter, using only one sensor and cable. They provide more intelligent and robust measurement systems, while saving cable weight and hardware complexity. Multidimensional sensors provide 2-D or 3-D information of the plant exterior. They, similarly eliminate the need of numerous single-point sensors and their cables. They provide more information with less hardware.

Non-intrusive sensors are beneficial for monitoring the internal component structural and operational parameters. They do not require holes through the housing. This eliminates parasitic pressure drops, the potential for sensor port leaks and catastrophic sensor fractures. Nonintrusive sensors improve the safety and performance of propulsion and power-conversion systems. The nonintrusive sensors eliminate the need of leak and FOD inspections of sensor ports, which enhances the operability and reduces the maintenance of the system.

\section{Nonintrusive Magnetic Sensors}

Nonintrusive variable-reluctance magnetic sensors generate an electric signal when an electrically conductive blade is passing in front of them, as shown in Fig 1 .

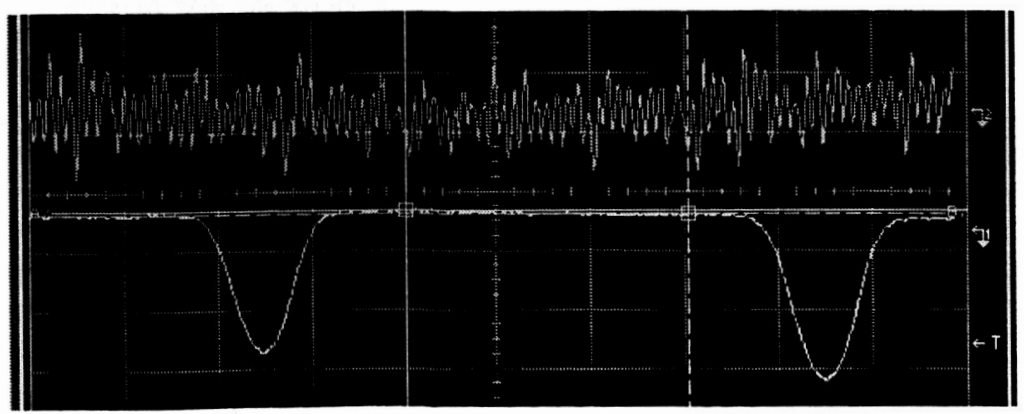

Figure 1. Unamplified signal from Delta II engine turbine. 
Blade vibration also generates a signal but at much higher frequency. Robust, high- temperature, high-frequency, high-sensitivity and miniature sensors have been developed at Rocketdyne. Figure 2 shows a $1 / 4$-inch diameter, $400-\mathrm{F}, 100-\mathrm{KHz}$ all-metal housing Rocketdyne-developed variablereluctance sensor.

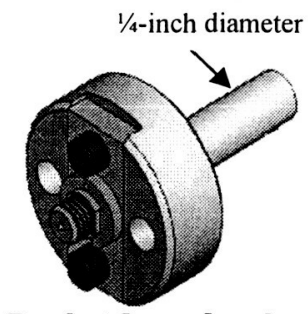

Figure 2. Rocketdyne developed 1/4-inch diameter sensor.

This technology provides direct blade-by-blade resonance data, allowing the user to isolate the fault to an individual blade. This type of sensors were used to obtain blade-tip resonance amplitude and frequency data at Rocketdyne Whirligig Facility, as shown in Figure 3, without contacting the blades. The blisk, consisting of the disc and blades, is shown in Figure 4.
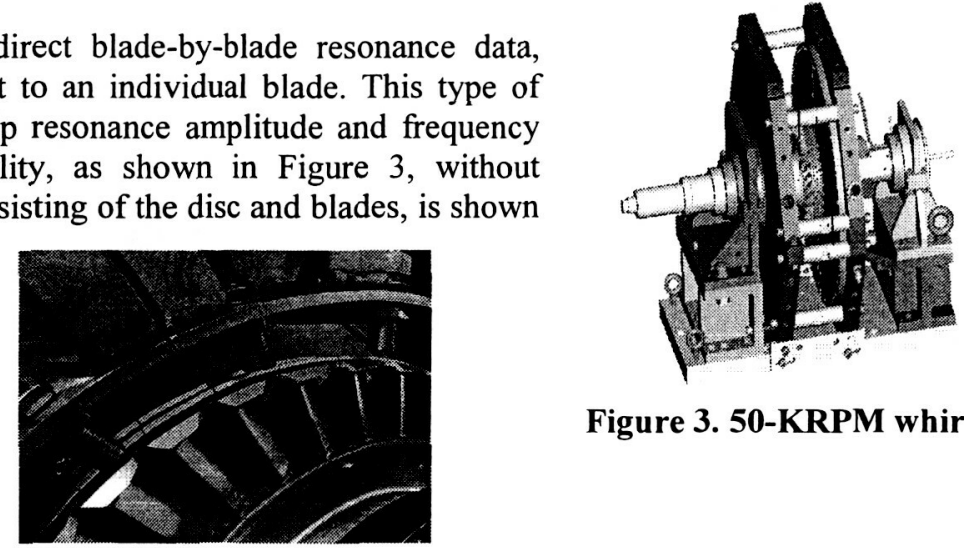

Figure 3. 50-KRPM whirligig.

Figure 4. Test blisk with three sensors.

The data was compared with the measurement of individual blade strain, using epoxied intrusive strain gauges and fragile rotary slip rings. The results were almost identical. Both techniques indicated approximately 300 microstrains in a blade in the same revolutions per minute (RPM) range. See Figure 5.

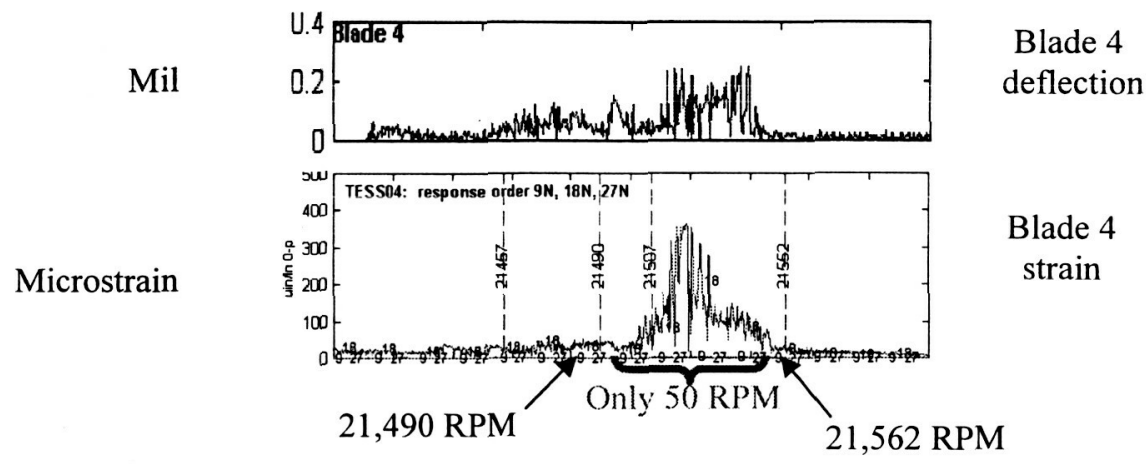

Turbine Figure 5. Individual Blade Stress and Deflection.

This capability allows calculation of fatigue life by combining the resonant frequency, amplitude and duration data. In addition, it has experimentally been demonstrated that seeded flaws in blades cause changes in the frequency and amplitude of resonance. This information could also be used for life determination, prediction and confirmation. The same sensor could also be used for RPM and blade-gap measurements, providing multifunctional data. Furthermore, additional variable-reluctance magnetic sensors can also measure radial and axial turbopump runouts, torque and horsepower. They could eliminate the need of intrusive inspection of the turbine/pump blades/impellers.

\section{Multidimensional Remote Sensors}

Remote sensors could be used to provide 3-D information of the exterior of propulsion and powerconversion systems. Today, only single-point measurements are obtained. The remote sensors eliminate parasitic pressure drops, the potential for sensor port leaks and catastrophic fractures; thus, improving the safety and performance of the propulsion and power-conversion systems. 
An example of such a technology is fiberoptic (FO) spectrometry. It provides an overall health assessment means of the internal components. Commercial off-the-shelf (COTS) fiberoptic spectrometers, as shown in Fig 6, contain a diffraction grating and 4096-diode linear-array photodetector. The grating diffracts the light transmitted by FO cable to different colors at different angles. The photodetector array, placed in front of the diffracted light, measures the amplitude of each color simultaneously. An electronic multiplexer provides consecutive electrical spectra in only five milliseconds, covering 300 to 800 nanometers. The spectral wavelengths are an indication of the combusting element types and the intensity of each wavelength is a measure of the amount of that element.

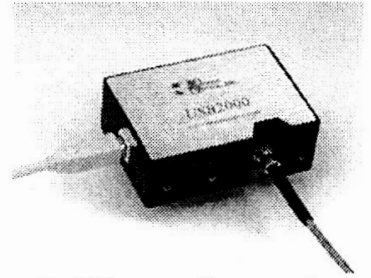

Figure 6. Fiberoptic spectrometer.

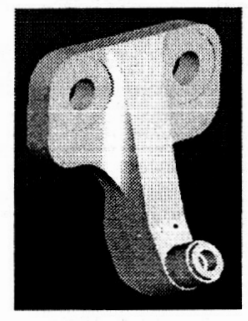

Figure 7. Rocketdyne-developed fiberoptic spectrometer probe. complexities.

A spectrometric system was developed at Rocketdyne using a robust probe, shown in Fig 7, 100-ft long FO cable, shown in Fig 8, and ruggedized COTS FO spectrometers. The spectrometer probe, located at the bottom lip of Space Shuttle Main Engine (SSME) nozzle is oriented in a direction that detects plume optical intensity above the shock diamond, eliminating shock-diamond mechanical tracking

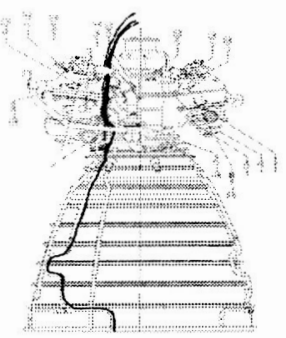

Figure 8. Fiberoptic cable routing on Space Shuttle Main Engine.

These systems detected simultaneously $\mathrm{Ni}, \mathrm{Cr}$, and $\mathrm{Fe}$ elements from Inconel-powder-containing uralite paste, applied to the inner wall of the SSME nozzle, almost instantaneously. Fig 9 shows the spectra of a seeded and unseeded SSME plume.

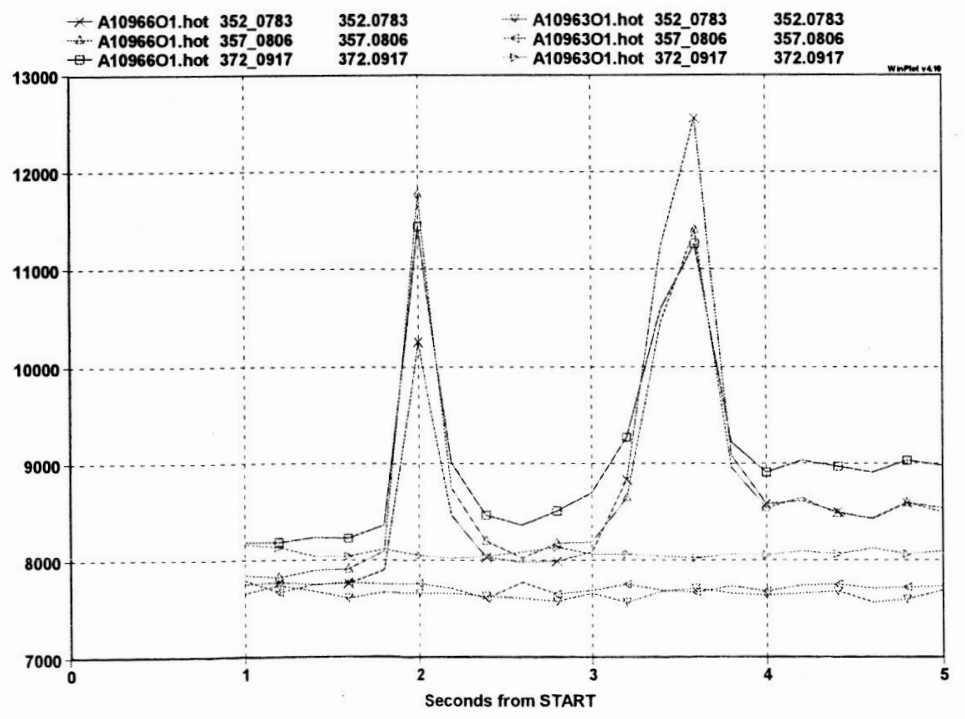

Figure 9. Seeded and unseeded SSME plume spectra. 


\section{Other Multidimensional Remote Sensors}

Rocketdyne has also developed remote external-leak imaging techniques, optically monitoring the leak using special cameras. Leaks as small as a fraction of a standard cubic inch of $\mathrm{H} 2, \mathrm{~N} 2, \mathrm{O} 2, \mathrm{H} 2 \mathrm{O}$, and $\mathrm{CO} 2$ have already been mapped in 2-D, in a laboratory environment. These leaks could simultaneously be imaged, using only one camera.

\section{B. Algorithms}

There are many powerful algorithms that can be useful for better control, health-monitoring and real-time inspection of deep-space propulsion and power-conversion systems. They could provide information for reliable long-duration missions. They include multivariable, adaptive, ac-component-based derivative, data-fusion algorithms, etc.

An application of adaptive-control algorithms could be the detection of resonant blade anomalies. If a blade resonates violently at a given RPM, the rotary speed can be changed to detune that blade resonance. This may cause resonance of another blade that hopefully has not operated in resonant mode extensively. This self-repairing approach increases the over-all life of the blisk, allowing successful completion of long-duration missions. In the tests conducted at Rocketdyne Whirligig Facility, at least 8 times higher deflection amplitude was observed at resonant frequency. Fig 10 shows blade \#13 deflecting up to 0.4 mils at approximately $21,540 \mathrm{RPM}$, whereas at only 30 RPM higher or 20 RPM lower operation, the deflection is almost zero.

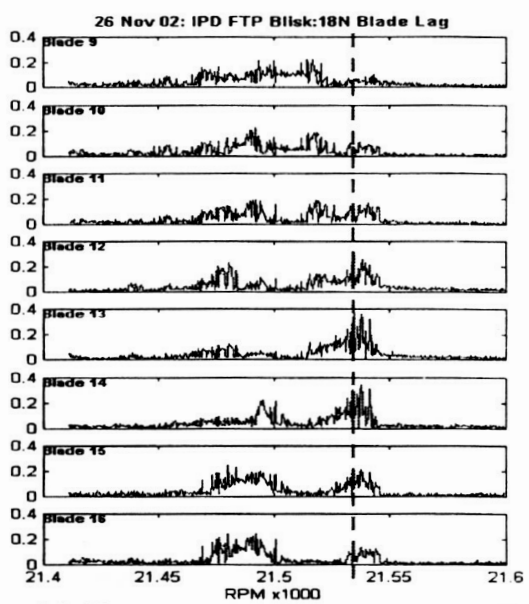

Figure 10. Resonance amplitude variation at different RPM.

It might also be needed to constantly dither the RPM. This type of algorithm could, for example, reduce the dwell time of each blade in its resonant frequency and extend the life of the blisk.

\section{Conclusion}

Advanced measurement, algorithm and control technologies are needed for safer deep-space on-board propulsion and power-conversion HMS/inspection systems. Comprehensive autonomous HMS/inspection systems are needed to reduce the life cycle cost of propulsion and power conversion systems. Presently, these technologies are not at Technology Readiness Level (TRL) six. Measures must be taken soon to develop these technologies for long-duration space-exploration missions. These technologies require extensive testing to generate confidence in the designers to incorporate them in deep-space propulsion and power-conversion systems.

New nonintrusive, multidimensional, direct, multifunctional and robust sensors are needed for these systems. Furthermore, novel technologies such as nanosensors, lasers, microprocessors, ultrasonics, optical, electromagnetic, etc, should also be thoroughly evaluated and promising ones developed immediately to a TRL of six before the design of the hardware starts. These measurement technologies should collectively be able to monitor all potential failure modes of propulsion and power-conversion systems with very high sensitivity and speed to allow early detection and timely fault mitigation for these demanding missions.

Advanced multivariable, data-fusion, dithering and adaptive control/HMS algorithms must also be tested extensively under adverse extreme cases in simulation laboratories. By injecting faults and improving the validity of the response, the confidence in their stability and utility will increase. This type of control system has never been used in aerospace applications.

\section{Acknowledgments}


The author would like to thank Jerry Jackson for supporting the development of these technologies and Mr. Raffi Ohanians and Kelly Stallmo for their assistance in preparing this paper.

\section{Bibliography}

Pettit, C. D., S. Barkhoudarian, A. G. Daumann, Jr., G. M. Provan, Y. M. El Fattah and D. E. Glover, "Reusable rocket engine advanced health management system: Architecture and technology evaluation summary," AIAA-992527, AIAA/ASME/SAE/ASEE Joint Propulsion Conference and Exhibit, Los Angeles, California, June, 1999

Barkhoudarian, S., G. S. Cross, and C. F. Lorenzo, "Advanced instrumentation for next-generation aerospace propulsion control systems," AIAA-93-2079, AIAA/SAE/ASME/ASEE Joint Propulsion Conference and Exhibit, Monterey, California, 1993.

Ezell, W., S. Barkhoudarian, and G. Gross, "Health monitoring of reusable rocket engines," SAE, Aerospace Atlantic Conference, Dayton, Ohio, April 7-10, 1992.

Delcher, R., A. Dergevorkian, and S. Barkhoudarian, "Fiberoptics for liquid propellant rocket engine environments," AIAA-89-2416, AIAA/ASME/SAE/ASEE $25^{\text {th }}$ Joint Propulsion Conference, Monterey, California, July 10-13, 1989.

Randall, M. R., S. Barkhoudarian, J. J. Collins, and C. Martinez, "Condition monitoring instrumentation for space vehicle propulsion system," Advanced Earth-to-Orbit Technology Conference, Huntsville, Alabama, May, 1988.

Barkhoudarian, S., B. Szemenyei, R. S. Nelson, R. Pauckert, and T. Harmon, "Improved maintainability of spacebased reusable rocket engines," AIAA-88-3113, AIAA/ASME/SAE/ASEE Joint Propulsion Conference, Boston, Massachusetts, 1988.

Randall, M. R., S. Barkhoudarian, J. J. Collins, and A. Schwartzbart, "Noncontacting measurement technologies for space propulsion condition monitoring," Joint Army-Navy-NASA-Air Force Interagency Propulsion Committee, Propulsion Meeting, San Diego, California, December 15-17, 1987.

Maram, J., and S. Barkhoudarian, "Progress toward an advanced condition monitoring system for reusable rocket engines," Joint Army-Navy-NASA-Air Force Interagency Propulsion Committee, Propulsion Meeting, San Diego, California, December 15-17, 1987.

Collins, J., S. Barkhoudarian and M. Randall, "Improvements in reusable rocket engine operational effectiveness using condition monitoring," AIAA-86-1411, AIAA/ASME/SAE/ASEE Joint Propulsion Conference, Huntsville, Alabama, 1986.

Barkhoudarian, S., and A. T. Zachary, "Condition monitoring for space-based reusable rocket engines," ASME Winter Annual Meeting, New Orleans, Louisiana, December, 1984. 